\title{
A Amazônia na geopolítica mundial dos recursos estratégicos do século XXI
}

The Amazon in World Geopolitics of the Strategic Resources of the Twenty-first Century

L'Amazonie dans la géopolitique mondiale des ressources stratégiques du Xxième siècle

\section{Mario Miguel Amin}

\section{OpenEdition}

\section{Journals}

Edição electrónica

URL: http://journals.openedition.org/rccs/5993

DOI: $10.4000 /$ rccs.5993

ISSN: 2182-7435

Editora

Centro de Estudos Sociais da Universidade de Coimbra

\section{Edição impressa}

Data de publição: 1 setembro 2015

Paginação: 17-38

ISSN: 0254-1106

\section{Refêrencia eletrónica}

Mario Miguel Amin, "A Amazônia na geopolítica mundial dos recursos estratégicos do século xxı », Revista Crítica de Ciências Sociais [Online], 107 | 2015, posto online no dia 04 setembro 2015, consultado o 10 dezembro 2020. URL : http://journals.openedition.org/rccs/5993 ; DOI : https:// doi.org/10.4000/rccs.5993 


\title{
MARIO MIGUEL AMIN
}

\section{A Amazônia na geopolítica mundial dos recursos estratégicos do século XXI}

\begin{abstract}
O objetivo do presente artigo é discutir a posição geopoliticamente estratégica da região amazônica diante da perspectiva global de escassez de recursos naturais necessários para o crescimento da economia mundial no século XXı. O paradigma da globalização definiu, a partir dos anos 1980, uma nova configuração geopolítica determinada pela crescente demanda internacional por recursos naturais estratégicos. Nessa nova conjuntura global, a busca por "territórios vitais" torna-se fator crítico para aquelas economias hegemônicas que, durante séculos, têm determinado o rumo do comércio internacional. Nesse processo, as regiões ricas em recursos estratégicos passam, assim, a ser o centro das atenções internacionais. A região Amazônica, detentora do maior estoque de recursos estratégicos - água, minerais, biodiversidade - do planeta, passa a constituir o espaço vital do século XXı. Determina-se, assim, uma nova realidade geopolítica para a região Amazônica, exigindo maior presença do Estado visando não só seu crescimento econômico e desenvolvimento sustentável como também reafirmar a soberania da região.
\end{abstract}

Palavras-chave: Amazônia; geopolítica; globalização; recursos naturais; soberania regional.

\section{Introdução}

Durante as últimas décadas, o avanço internacional dos países hegemônicos foi determinado por questões fundamentadas em dois aspectos: primeiro, no relacionado à organização e controle das ideologias regionais, e em segundo lugar, às ações políticas visando ao equilíbrio regional do poder. Esse contexto, entretanto, foi radicalmente alterado pelo novo processo de relações internacionais estabelecido, a partir dos anos oitenta do século xx com o paradigma da globalização. A globalização promoveu a integração das economias, abrindo oportunidades para aqueles países que estavam preparados para incorporar, de modo geral, os ganhos potenciais advindos do aumento da produtividade, da redução da pobreza, da melhoria na educação e, especialmente, da incorporação de uma dinâmica industrial de alta tecnologia. 
Essa mudança alterou radicalmente a participação espacial da geografia do comércio internacional, forçando as corporações a buscar novos mercados e redistribuir os investimentos internacionais. Os governos, por sua vez, foram obrigados a definir novas políticas nacionais e novas formas de relacionamento internacional para enfrentar a forte competição, no mercado internacional, por matérias-primas estratégicas. Novos modelos de desenvolvimento e crescimento econômico foram exigidos e implementados tendo como base o paradigma da globalização. A globalização passou a acelerar a criação de uma nova ordem mundial fundamentada na capacidade tecnológica, evidenciando a importância da biotecnologia, da engenharia genética e da tecnologia da informação. Nesse ambiente, o setor industrial teve que desenvolver uma capacidade inovadora e tecnológica para permanecer competitivo no mercado internacional.

O aumento na competição internacional gerou uma significativa pressão por novas fontes de matérias-primas, como petróleo, gás, minerais da terceira geração e, especialmente, por fontes alternativas de suprimento de água. Recursos esses necessários para atender a crescente demanda das economias tradicionalmente dominantes do mercado internacional de commodities, como também daquelas economias que, em função do paradigma da globalização (Stiglitz, 2003; Letchner, 2009), aproveitaram as condições econômicas e políticas para se integrar ao seleto grupo de economias que determinam a geopolítica mundial do fluxo e intercâmbio de recursos naturais.

Nesse contexto, os países ricos em recursos naturais se confrontam com uma nova ordem internacional, intensiva no uso de matérias-primas estratégicas, que passa a determinar a regionalização geopolítica dos padrões de exploração e comercialização internacional do século XXI. A região Amazônica, detentora do maior estoque de recursos estratégicos - água, minerais e biodiversidade - do planeta, passou a ser o centro das atenções internacionais. Configura-se, assim, uma nova realidade geopolítica para a Amazônia, exigindo suas grandes riquezas maior presença do Estado na região, assim como a instrumentalização de políticas que visem a alavancar não só seu crescimento social e econômico, mas também seu desenvolvimento sustentável. Dessa forma, o objetivo deste trabalho é discutir a posição geopoliticamente estratégica da Amazônia diante da perspectiva global de escassez de recursos naturais necessários para o crescimento da economia mundial no século XXI.

O presente artigo passa a discutir a nova ordem global determinada pelo paradigma da globalização. Depois, procura-se analisar a importância geopolítica da Amazônia no cenário internacional e sua posição estratégica diante do novo contexto de crescimento global, ao que se seguirão as considerações finais. 


\section{Definindo uma nova ordem global}

Historicamente, o mundo sempre foi dividido em regiões estrategicamente localizadas e militarmente protegidas para fornecer os recursos naturais necessários à sobrevivência dos padrões de desenvolvimento e crescimento econômico dos países hegemônicos. Esse contexto foi mantido e protegido por um número de países que, em função de sua supremacia militar, conseguiram implantar e manter certo domínio sobre importantes territórios caracterizados por ambientes ricos em recursos estratégicos, assim como controlar diferentes rotas marítimas importantes para os fluxos de mercadorias. Nesse contexto, destacam-se importantes estrategistas geopolíticos que definiram, durante os séculos XIX e XX, a diplomacia do "poder territorial global”. Ratzel, ao definir o Estado como um organismo vivo, exemplifica a necessidade da conquista ou expansão do espaço vital. Mahan, importante estrategista naval dos Estados Unidos da virada do século Xx, define como ponto central da política externa do país a expansão do poder marítimo, permitindo, assim, o controle estratégico e global de determinados territórios nas regiões da América Latina e Ásia. Outro estrategista que teve importante participação na consolidação da geopolítica territorial foi Mackinder, que, em seu trabalho de 1904, The Geographical Pivot of History, apresenta a importância do heartland como região estratégica para o Império Britânico (Tosta, 1984).

De modo não diferente dos séculos anteriores, o século XXI apresenta um novo panorama mundial pela disputa dos recursos naturais. O extraordinário crescimento da economia mundial, a partir de 1980, obrigou as potências hegemônicas, especialmente os Estados Unidos, a definir políticas destinadas a encontrar e a assumir a posse de regiões ricas em fontes de energia e recursos alternativos para manter suas economias competitivas. Isso foi necessário pelo surgimento de novas economias globais como os BRICS - Brasil, Rússia, Índia, China e África do Sul -, cujas políticas dirigidas a fortalecer o setor de exportações de produtos industrializados e principalmente de commodities alteraram significativamente o fluxo do comércio internacional. Por causa dessa nova divisão do mercado internacional do trabalho, a forma de apropriação de áreas ricas em recursos, por parte das economias hegemônicas, incentivou uma nova estrutura global em que os conflitos armados passarão a definir a formação de espaços vitais estratégicos de recursos naturais.

\section{Os espaços vitais de recursos naturais estratégicos}

Duas regiões se apresentam geopoliticamente como espaços vitais na luta pelos recursos estratégicos do século XXI: a região formada pela Ásia Central 
e a bacia do mar Cáspio e a região Amazônica. Nesse contexto, os países ricos em recursos naturais se confrontam pelo surgimento de uma abordagem geopolítica na qual uma nova ordem internacional, intensiva no uso de recursos naturais, passa a determinar a regionalização dos padrões produtivos internacionais do século XXI.

A Ásia Central e a bacia do mar Cáspio detêm as maiores reservas de hidrocarbonetos do mundo. Em relação a essa região, existe a frase histórica de Mackinder, que refere que "quem domine essa região dominará o mundo". Com fronteiras para a Rússia e a China, essa região abriga os antigos países que durante anos formaram parte da União Soviética: Cazaquistão, Uzbequistão, Turcomenistão, Tadjiquistão e Quirguistão. Ricos em recursos naturais, esses países têm-se convertido no beartland de grandes investimentos estrangeiros, assim como em importantes centros para venda de equipamentos militares. Toda a atenção está voltada, hoje, para essa região, de modo a entender e definir sua situação na geopolítica mundial e, principalmente, no relacionado ao seu futuro, visto que durante séculos tem sido alvo das maiores aventuras bélicas por parte das potências militares.

No outro extremo do planeta, a Amazônia, que tem sido também durante séculos objeto dos mais diversos e excêntricos comentários, é um importante espaço vital por sua grandiosidade territorial, sua riqueza de recursos naturais e a exuberância de sua biodiversidade. Pela potencialidade do estoque de recursos estratégicos necessários para a geração das inovações tecnológicas, a Amazônia passou a atrair as atenções internacionais, pelas riquezas do subsolo regional e, especialmente, pelo seu grande potencial hídrico. Essa riqueza tem motivado muita preocupação nacional, mas especialmente internacional, sobre a maneira como seus vastos recursos naturais poderiam ser aproveitados de forma sustentável. Portanto a Amazônia confronta-se, hoje, com cenários internacionais bastante conflitantes nos quais prevalece o paradigma do desenvolvimento sustentável.

A sobrevivência do poder hegemônico de países como Inglaterra, França, Alemanha e Estados Unidos depende do acesso à vasta fronteira internacional de recursos naturais estratégicos. A Amazônia guarda um grande estoque desses recursos, passando a ser, portanto, centro de referência nas políticas de planejamento estratégico por parte de economias hegemônicas, como a dos Estados Unidos, na busca de regiões ricas em recursos naturais no século XXI.

Michael T. Klare (2008), professor de Estudos sobre Paz e Segurança Mundial no Hampshire College (Estados Unidos), em seu artigo sobre "a nova geopolítica da energia", define a estratégia segundo a qual os Estados Unidos deverão seguir da seguinte forma nos próximos anos para manter seu poder hegemônico sobre os recursos naturais: 
Enquanto a atenção diária do exército norte-americano está concentrada no Iraque e Afeganistão, os estrategistas norte-americanos olham para além destes dois conflitos com o objetivo de prever o meio em que irá ocorrer o combate global em tempos vindouros. E o mundo que eles enxergam é um no qual a luta pelos recursos vitais - mais do que a ideologia ou a política de equilíbrio de poder - domina o campo da guerra. Acreditando que os EUA devam reconfigurar suas doutrinas e forças para prevalecer em semelhante entorno, os oficiais mais veteranos deram os passos necessários para melhorar seu planejamento estratégico e capacidade de combate.

A importância geopolítica dos recursos naturais e em especial da região Amazônica para a manutenção hegemônica dos Estados Unidos é muito bem colocada por Cohen da seguinte maneira:

A visão dos EUA sobre a importância econômica da América do Sul foi fortemente influenciada pelo aparente potencial da bacia Amazônica (também referida como "Amazônia” ou “Amazonas"). Há muito tempo ela era considerada uma das regiões mais ricas do mundo, com vastos e inexplorados recursos minerais, florestais e agrícolas e com acesso a transporte marítimo. $(2003: 361)^{1}$

As afirmações de Klare e Cohen, dentro da nova ordem geopolítica que prevalece no momento, representam a formulação de uma luta futura pela apropriação dos recursos naturais em qualquer territorialidade geográfica, independentemente dos impactos sociais, econômicos e ambientais que possa causar.

O surgimento de novas potências econômicas como a China colocou uma enorme pressão na demanda mundial por recursos naturais estratégicos, definindo uma nova conjuntura internacional em que as forças do mercado procuram fontes alternativas de suprimento de recursos visando a atender as necessidades econômicas e produtivas. A China, com uma economia voltada para o mercado externo, tem pressionado significativamente a demanda internacional por recursos naturais em seus mais diversos setores. A importação de minerais destinados às indústrias siderúrgicas e para a construção de infraestrutura portuária foi priorizada pelo Governo. Outros setores como alimentos e hidrocarbonetos representam importantes commodities na pauta de importação da China.

A entrada da China no seleto grupo de grandes potências econômicas hegemônicas do mundo contextualiza uma nova realidade global, na qual regiões ricas em recursos naturais estratégicos passam a ser o alvo das

${ }_{1}^{1}$ Tradução do autor. 
políticas externas do Governo chinês. A nova diplomacia da China foca suas atenções nas regiões da África, especialmente na área subsaariana, onde tem sido ator principal ao reativar um novo Scramble for Africa chamado de Land Grabbing. Na América do Sul, as aproximações políticas têm sido concentradas em países com grandes áreas de produção de alimentos, como a Argentina e o Brasil, passando, assim, a competir diretamente pelo acesso aos recursos estratégicos regionais com os países europeus e, especialmente, com os Estados Unidos. Neste sentido, uma nova conjuntura geopolítica por recursos naturais estratégicos passa a ser definida no século XXI, no território sul-americano.

\section{Importância geopolítica da Amazônia}

A importância geopolítica da Amazônia no cenário internacional tem sido determinada por seu grande estoque de recursos estratégicos, que despertam interesses expressos nas estratégias geopolíticas de países e instituições internacionais, pela apropriação do que os grupos de ecologistas e ambientalistas chamam hoje de "capital natural ou capital intangível" (Becker, 2004; Schmidt e Santos, 2002). A Amazônia, como não podia ser diferente, ganhou novas formas de ser identificada nos eventos nacionais e internacionais: "Amazônia, maior floresta de capital natural"; "Qual é o valor intangivel da Amazônia?". Essas e muitas outras identidades surgiram ao longo do tempo como forma de qualificar o patrimônio da maior floresta tropical do planeta.

No entanto, a partir de 2000, na estrutura do comércio internacional, uma nova forma de tratar a dinâmica do mercado foi definida como "a mercantilização da natureza". Becker explica muito bem esse novo processo, no qual a Amazônia passa a ser o centro mundial do "mercantilismo do capital natural". A autora indica que:

nos últimos anos, novas tendências se delineiam no sentido de viabilizar a realização do capital natural através de um processo crescente de mercantilização da natureza. Alguns de seus elementos estão em vias de serem transformados em mercadorias fictícias e objeto de mercados reais, afetando intensamente a Amazônia. (2004:39)

Nesse contexto, a Amazônia, diante da forte pressão global pela disponibilidade de recursos naturais estratégicos para a manutenção do padrão de desenvolvimento e crescimento econômico, assume, no século XXI, importância geopolítica mundial, exigindo iniciativas administrativas e políticas, por parte dos governos, para garantir a soberania na conservação e na utilização 
dos recursos naturais. Assim, como Becker (2005) indica, a Amazônia passa a ser, no novo âmbito global, a grande fronteira do capital natural.

\section{Os recursos estratégicos do século xxI}

A seguir, discute-se a posição estratégica da Amazônia na nova ordem mundial, definida pela importância de suas riquezas naturais - biodiversidade, minerais e água. Pretende-se, assim, identificar e mensurar o potencial da região Amazônica dentro de uma nova ordem mundial moldada não somente nos "discretos" avanços territoriais, mas também nas pressões sobre novos espaços ou ecossistemas das regiões tropicais.

\section{Biodiversidade}

Discutir a biodiversidade como recurso estratégico do século XXI implica, necessariamente, retornar ao ano de 1800, quando Alexander Von Humboldt, famoso naturalista alemão, percorreu, em companhia do botânico francês Aimé Bonpland, os rios da região Amazônica, pesquisando as diferentes espécies de plantas. Humboldt, ao conhecer essa enorme floresta tropical, não resistiu à sua enorme diversidade de vida natural, passando a chamá-la de Hileia, termo que passou a ser internacionalmente usado como sinônimo da Amazônia.

Essa atenção especial dada por Humboldt à Amazônia tem sido reproduzida pelos mais diversos cientistas do mundo que veem, na biodiversidade da região, o principal ecossistema do planeta para manter a diversidade e a qualidade de vida do homem. Revilla exemplifica, em seu livro Plantas da Amazônia: oportunidades econômicas e sustentáveis, esse pensamento quando diz que:

a gigante Amazônia ainda possui extensa área de densa floresta tropical, alta diversidade de espécies de animais e vegetais, distribuídas numa grande variedade de ecossistemas terrestres e aquáticos, traduzindo-se assim em um enorme potencial econômico e de recursos genéticos no presente e para o futuro. (2000: 11)

A proteção da biodiversidade tem sido tema central de vários eventos nacionais e internacionais nos quais têm sido identificados fatores político-econômicos, fatores socioculturais e fatores biológicos como agentes diretamente relacionados à utilização dos serviços da floresta Amazônica (Lavilla, 1996). Nesse sentido, a Convenção de Diversidade Biológica (CDB), firmada durante a Rio-92 e ratificada em 1993, é bem específica em seu Artigo 15, Acesso a Recursos Genéticos, quando regula e protege, em seus parágrafos 1, 4 e 5 , o acesso à biodiversidade, por partes externas, da seguinte maneira: 
1. em reconhecimento dos direitos soberanos dos Estados sobre seus recursos naturais, a autoridade para determinar o acesso a recursos genéticos pertence aos governos nacionais e está sujeita à legislação nacional;

[...]

4. o acesso, quando concedido, deverá sê-lo de comum acordo e sujeito ao disposto no presente artigo;

5. o acesso aos recursos genéticos deve estar sujeito ao consentimento prévio fundamentado da Parte Contratante provedora desses recursos, a menos que de outra forma determinado por essa Parte.

A complexidade do controle ambiental, no Brasil, tem sido a grande preocupação de diversos órgãos governamentais e não governamentais na perspectiva de definir políticas dirigidas a tomar ações concretas para controlar a perda da biodiversidade da região Amazônica. Essa preocupação é expressa nos estudos promovidos pelo Ministério do Meio Ambiente do Brasil (2001), por meio do Programa Nacional de Diversidade Biológica (Pronabio), visando a subsidiar as ações necessárias ao cumprimento das obrigações do país junto à Convenção sobre Diversidade Biológica, firmada durante a Rio-92. Entre os principais resultados do estudo, destaca-se a identificação dos eixos e polos de desenvolvimento que teriam impacto direto na geografia da biodiversidade da região Amazônica. O Pronabio, entretanto, não tem representado, para alguns autores, um projeto dirigido para a preservação da floresta amazônica.

A posição mais direta sobre o significado da falta de uma política nacional sobre proteção à biodiversidade da Amazônia é expressa por Ribeiro (2006: 240), ao comentar os resultados do Seminário Internacional sobre o Meio Ambiente, Pobreza e Desenvolvimento da Amazônia (SINDAMAZÔNIA), realizado em Belém, em fevereiro de 1992. O autor é enfático ao comentar que:

todos os estudos ressaltam um problema de alto significado geopolítico para a Amazônia: a incapacidade do Brasil para formular uma política de controle e manejo da biodiversidade da Região, seja por falta de recursos financeiros, seja por falta de pessoal técnico e científico qualificado. Todos insistem na indispensabilidade de cooperação dos países ricos, quanto à oferta de recursos financeiros e de pessoal especializado; essa oferta tem havido, mas, evidentemente, é insuficiente para realizar tão gigantesco trabalho; e os recursos financeiros, os países ricos, em geral, só oferecem para os próprios cientistas atuarem na Região, orientando sempre a aplicação desses recursos para programas e projetos de seu imediato interesse. Isso naturalmente gera problemas geopolíticos graves e, em princípio, inaceitáveis. 
A região Amazônica, com a maior floresta tropical do planeta, detém o maior estoque de recursos estratégicos do século XXI, portanto, políticas mais responsáveis devem ser um componente da geopolítica do país, objetivando reduzir as perdas do bioma da Amazônia, para mostrar, no âmbito internacional, a responsabilidade para com as futuras gerações dentro do marco definido pelo Relatório da Comissão Mundial para o Ambiente e o Desenvolvimento "Nosso Futuro Comum", em 1987.

Outro ponto que vem se tornando muito polêmico dentro das estratégias para a preservação da biodiversidade diz respeito ao que passou a ser definido como biopirataria. Esse tema tem sido muito discutido por muitos autores, chamando a atenção para as perdas que o Brasil pode ter, no futuro, ao não proteger seu estoque de recursos estratégicos. Shiva comenta, em seu livro Biopirataria: A pilhagem da natureza e do conbecimento (2001: 92), as implicações da globalização e das inovações da engenheira genética sobre o patrimônio das florestas tropicais em geral, da seguinte maneira: "o surgimento de novos sistemas de propriedade intelectual, e de um novo e acelerado potencial de exploração da biodiversidade, cria novos conflitos em relação a ela - entre a propriedade privada e a propriedade comunitária, entre uso global e local".

Nos anais históricos sobre a Amazônia, menciona-se o caso do inglês Henry Alexander Wickman que em 1876 coletou milhares de sementes de Hevea brasiliensis na região dos rios Madeira e Tapajós, levando-as para Kew Garden na Inglaterra para, posteriormente, serem levadas as mudas para o Ceilão, no Oriente. Adaptadas ao ambiente regional, a produção de borracha na Ásia tornou-se comercial, concorrendo diretamente com a produção extrativa da Amazônia. O final da história é muito bem conhecido por todos (Ribeiro, 2006).

Os casos de apropriação dos recursos genéticos da Amazônia não pararam no caso da seringueira. Informações sobre a apropriação indevida da biodiversidade da região amazônica são notícias habituais nos principais meios de comunicação. Alguns exemplos podem ser citados aqui como referências de um processo de avanço discreto sobre o patrimônio genético da Amazônia. O acesso à biodiversidade e a transferência de recursos genéticos para outros países de forma direta ou indireta são discutidos amplamente por Gama (1997) em sua pesquisa sobre o Projeto Dinâmica Biológica de Fragmentos Florestais (PDBFF), proposto em 1978, concebido nos Estados Unidos. O autor conclui que, entre os participantes brasileiros e estrangeiros do projeto de pesquisa, o segundo grupo foi mais beneficiado pela cooperação internacional e, entre os estrangeiros, os norte-americanos foram os que se beneficiaram mais no PDBFF, ficando com a maior parte do que foi coletado para análise. 
Mais recentemente, foi divulgado, no site Inovação Tecnológica (2008), que o sonho dos cientistas seria a produção de computadores ópticos ultrarrápidos, mas que por não terem acesso a um cristal fotônico ideal capaz de manipular a luz visual, o projeto não tinha evoluído durante os últimos anos. O site publicou, em 3 de junho de 2008, importante notícia indicando que pesquisadores da Universidade de Utah nos Estados Unidos tinham encontrado o cristal ideal na natureza, mais especificamente na carapaça de um besouro brasileiro, o Lamprocyphus augustus. O importante dessa história, como comenta o site, é que os pesquisadores não tiveram que vir ao Brasil para coletar o besouro, ele foi simplesmente encomendado a um vendedor de insetos da Bélgica, que vende insetos pela internet.

\section{Minerais}

Cada época industrial é marcada por determinados tipos de materiais que passam a ser elementos-chave para o desenvolvimento de novos e mais avançados produtos. Como não podia ser diferente, a Amazônia, além de ser detentora de uma grande biodiversidade em seu subsolo, detém a parte dos maiores estoques de recursos minerais necessários para os avanços tecnológicos do século XXI.

Um estudo realizado pelo Centro de Tecnologia Mineral (CETEM), em 1991, mostra as informações disponíveis a respeito dos recursos nacionais e, em especial, o potencial e a estrutura produtiva dos recursos minerais da Amazônia. As estatísticas mostram a região Amazônica com grandes estoques voltados para a exportação de ferro, bauxita, alumina, ouro, estanho, manganês, diamantes, gemas e pedras semipreciosas. Outros minerais conhecidos, mas ainda não explorados de forma intensiva, são o cromo, o cobre e o níquel (CETEM, 1991). A importância dessa riqueza mineral na economia internacional é observada por Dos Santos (1996: 177), quando explica que "os primeiros investimentos na Amazônia foram feitos por empresas estrangeiras, com o principal objetivo de verificar as potencialidades minerais dessa vasta região ainda desconhecida, considerando apenas seu uso futuro".

A região Amazônica detém uma das maiores províncias minerais do mundo: Carajás. Descoberta em 1967, a província revelou fabulosas jazidas de ferro situadas no sul do estado do Pará, entre os rios Araguaia e Xingu, abrangendo uma área de 120000 quilômetros quadrados. A maior parte dos minérios da Amazônia é encontrada em áreas com rochas do período pré-cambriano (Dos Santos, 1980). As reservas da província mineral de Carajás são as maiores do Brasil e podem ser consideradas, também, uma das maiores reservas do mundo. 
A riqueza mineral da Amazônia é descrita por Villas (2008: 78), na edição especial do Scientific American sobre a Amazônia, em que mostra o estado Amazonas com importantes jazidas de ferro, manganês e nióbio-tântalo. O estado de Rondônia aparece com ocorrências de ouro, titânio e diamantes. O estado de Roraima se destaca por uma riqueza mineral em que o ouro, diamantes e especialmente o nióbio-tântalo são importantes componentes do subsolo regional. O estado do Amapá, como indica Villas (2008), foi aquinhoado com reservas expressivas de caulim, ferro, manganês, ouro, bem como importantes reservas de diamantes, níquel e também grandes jazidas do importante mineral nióbio-tântalo. Este último, por exemplo, é considerado pela indústria espacial um importante ingrediente para a construção de naves espaciais devido a suas características de boa resistência tanto para altas como para baixas temperaturas.

O estado do Pará é a região com o maior potencial mineral do Brasil. Com jazidas estimadas para 100 anos, grandes empreendimentos estão previstos para extração de bauxita nos municípios de Juruti e Paragominas, assim como de cobre no município de Salobo. Em recente levantamento realizado pelo Departamento Nacional de Produção Mineral (DNPM), foram identificados 16 distritos mineiros, entre os quais estão em produção os distritos de Canaã dos Carajás, Ipixunas, Parauapebas e Oriximiná (MME - DNPM, 2006).

Toda essa riqueza mineral dá à Amazônia uma importante posição geopolítica no cenário internacional, como fonte de importantes minerais para o século XXI. Mas, como comenta Da Silva, o "processo de ocupação econômica da Amazônia sempre obedeceu à imposição de interesses exógenos ligados à ideologia do desenvolvimento e, por essa razão, nunca respeito o equilibrou ecológico, pois considerava a região apenas fonte de matérias-primas" (1996: 205). Essa riqueza exige, portanto, técnicas de exploração e exportação em que sejam incorporados processos ambientalmente sustentáveis, visando a garantir o desenvolvimento regional da Amazônia dentro da tão desejada nova ordem mundial de desenvolvimento sustentável.

\section{Água}

A escassez de água nas mais diversas regiões do planeta tem se convertido no tema mais importante à escala mundial. Nos últimos anos vêm sendo discutidas, no Fórum Mundial da Água, realizado pela ONU em Marrocos (1997), Holanda (2000), Quioto (2007) e, mais recentemente, em Marselha (2012), a disponibilidade de água para a sobrevivência do planeta e especialmente a sua acessibilidade como um direito da humanidade. A preocupação da ONU decorre das estatísticas internacionais que mostram um futuro 
bastante sombrio para determinadas regiões do planeta. Em seu World Water Development Report, 2012, a ONU enfatiza a importância da água para todos os setores da economia, especialmente para alcançar o desenvolvimento sustentável. O relatório da ONU destaca que as pressões decorrentes do esperado aumento populacional, para 2050, deverão forçar significativamente a disponibilidade de recursos hídricos, chegando a ponto de exigir, futuramente, drásticas mudanças na forma como a água é utilizada e usada para evitar crises e conflitos internacionais em diversas regiões do mundo (ONU, 2012).

Outras publicações das mais diversas instituições e autores enfatizam a dimensão que a escassez de água pode alcançar. De Villiers, por exemplo, comenta sobre a crise da água, no século XXI, da seguinte maneira:

os seres humanos podem viver um mês sem comida, mas morrerão em menos de uma semana sem água. Os seres humanos consomem água, desperdiçam-na, envenenam-na e, inquietantemente, mudam os ciclos hidrológicos, indiferentes às consequências: muita gente, pouca água, água nos lugares errados e em quantidades erradas. A população humana está crescendo explosivamente, mas a demanda por água está crescendo duas vezes mais rápido. (2002: 36)

O comentário de De Villiers é ressaltado também por Camdessus et al. de forma mais preocupante, quando indicam que:

mais de um bilhão de pessoas não tem acesso adequado e a um preço aceitável à água potável. Perto de dois bilhões e meio não dispõem de qualquer tipo de saneamento. A água é vida! A ausência da água é doença e morte [...] antes de ser um problema de recursos financeiros, o problema da água é primeiramente uma questão de boa administração, de coordenação e de mobilização de todos os atores no meio de uma cadeia complexa de participantes. $(2005: 11,13)$

A preocupação desses autores, entre outras, pode ser explicada pelas estatísticas sobre a distribuição da água nos diferentes continentes do planeta. A escassez de água é um processo gradativo que se intensifica pelo desperdício e mau uso, de forma que, aos poucos, os continentes vão sofrendo perdas de disponibilidade. Futuramente, em se mantendo as atuais condições de consumo de água, assim como uma maior utilização de recursos hídricos para atender a crescente demanda por alimentos nas regiões mais pobres da Ásia, África e América Latina, sérios conflitos regionais podem ser iniciados, gerando "uma crise global da água".

De acordo com o registrado no II Fórum Alternativo Mundial da Água (Tundisi, 2003), a situação já é crítica na República Popular da China, 
na Índia, no México e no Chifre da África, regiões nas quais os lençóis freáticos têm registrado queda de um metro por ano, acima da taxa natural de reposição, apontando uma grave crise num horizonte de 20 a 25 anos. Outras localidades atingidas são o Oriente Médio e o Norte da África. Em outras regiões, a população expandiu-se acima da capacidade de abastecimento, produzindo poluição e escassez, casos de Taiwan, da Austrália e das áreas centrais do Meio-Oeste americano.

Essa queda de disponibilidade é causada, principalmente, pelo fato de os recursos hídricos serem um dos motores do desenvolvimento econômico de quase todos os países, sobretudo nos setores da agricultura e da indústria. Dessa forma, o que desequilibra a relação entre oferta de água na natureza e a demanda mundial é o aumento do consumo, visto que, de toda a água doce disponível, $70 \%$ dela é destinada à agricultura, $22 \%$ vai para a indústria e apenas $8 \%$ é destinada ao uso individual (clubes, residências, hospitais, escritórios e outros).

A maior preocupação na atualidade é conciliar o consumo de água per capita com a escassez em determinadas áreas do planeta. A escassez já tem feito surgir situações de "hidroconflitos internacionais" em várias regiões do planeta. Podem ser mencionados, por exemplo, os casos de Síria, Iraque e Turquia, que há muito tempo vêm tendo desavenças sérias no que diz respeito à utilização das águas dos rios Tigre e Eufrates, cujas nascentes estão em território turco, mas cruzam áreas dos outros dois países (Gleick, 1993).

A escassez de água é vista hoje como uma futura causa para a geração de confrontos armados entre países. Becker comenta que: "sua valorização reside na ameaça de escassez decorrente do forte crescimento do consumo, a tal ponto que é considerada o 'ouro azul', capaz de, à semelhança do petróleo no século Xx, instigar guerras no século XxI” (2004: 43).

De Villiers ressalta, também, a dimensão dos conflitos futuros por causa da escassez de água, da seguinte maneira:

1. No norte da África, a escassez de água cria duas formas distintas de tensões:

- tensões internacionais entre Marrocos, Argélia, Tunísia e Líbia pelo uso de reservas e do lençol freático, tendo na Tunísia seu epicentro; e

- tensões internas entre setores sociais e econômicos em disputa pela água.

2. No Oriente Médio, além do caso de Israel, que disputa o controle das nascentes do Jordão com a Jordânia, a Turquia ameaça o controle das fontes do Eufrates, colocando a Síria e o Iraque em clara situação de dependência e alto risco.

3. Na América do Norte, o aproveitamento do Rio Bravo ou Grande, na fronteira dos EUA com o México, é uma fonte constante de atritos, com os desvios crescentes para a irrigação e o abastecimento das cidades e da agricultura norte-americanas. 
4. Na Ásia Central, o controle do Tibet/Pamir, de onde provêm as fontes dos rios que correm para a China, Paquistão e Índia, agudiza os conflitos na Cachemira, Nepal e Tibet.

5. Na África do Sul, a situação da Namíbia é crítica, enquanto todo o Sahel, franja entre o Sahara e a savana semiárida africana, ameaça alguns milhões de pessoas com a fome, assim como Chad, Mali, Niger e Líbia se enfrentam constantemente, visando ao controle de lagos e oásis do deserto. (2002: 37-38)

Mais recentemente, o importante relatório Global Water Security, publicado em fevereiro de 2012 pelo Intelligence Community Assessment (ICA), expressa as implicações e riscos estratégicos para os Estados Unidos diante da escassez global de água. O relatório discute de forma muito objetiva que os recursos hídricos são fixos e devem ser mais bem administrados, já que não podem ser aumentados. O relatório da ICA conclui de forma bem categórica que:

Durante os próximos 10 anos, muitos países importantes para os Estados Unidos vão ter problemas com água - falta de água, má qualidade da água, ou enchentes - correndo o risco de instabilidade e fracassos dos Estados, de aumento das tensões regionais, e de limitada cooperação com os Estados Unidos em importantes objetivos da política norte-americana. Até 2040, a disponibilidade de água doce não vai acompanhar a demanda por falta de uma gestão mais eficaz dos recursos hídricos. Os problemas da água irão dificultar a capacidade de países-chave produzirem alimentos e gerarem energia, o que representa um risco para os mercados globais de alimentos e para o crescimento econômico. Como resultado das pressões demográficas e de desenvolvimento econômico, o Norte da África, o Oriente Médio e o Sul da Ásia enfrentarão grandes desafios para lidar com os problemas de água. $(2012: 3)^{2}$

É importante observar que autores como Gleick (1993), Shiva (2002), Barlow e Clarke (2002), Klare (2002), UNESCO (2003), Clarke e King, (2005), entre outros, já tinham manifestado a mesma preocupação com a possível escassez de água em determinadas regiões do planeta e os conflitos armados que essa situação poderia fazer deflagrar. As observações dos autores passaram despercebidas talvez por não se caraterizarem, na época, geopoliticamente importantes para nenhum país, como no momento atual.

2 Tradução do autor. 


\section{A Amazônia e a crise da água}

Diante da forte possibilidade da existência de conflitos armados nas regiões deficitárias de suprimentos de água, qual o futuro reservado para a Amazônia, considerada a maior reserva hidrográfica do planeta?

Uma resposta a esse questionamento exige que sejam contempladas e consideradas as estatísticas que mostram o Brasil como o detentor das maiores reservas de água doce do planeta. Nesse inventário, são contempladas as bacias dos rios Amazonas, São Francisco, Tocantins-Araguaia, Parnaíba e Paraná. Complementando esse estoque de recursos estratégicos para o século XXI, estão os maiores aquíferos do mundo: o aquífero Guarani, com volume de água de 45 mil quilômetros cúbicos, a maior parte no subsolo brasileiro; e o aquífero Alter-do-Chão, com um volume de água de 86 mil quilômetros cúbicos, localizado nos estados do Amazonas, Pará e Amapá. Nesse contexto de riqueza hídrica, o rio Amazonas, com mais de três mil afluentes, assume posição privilegiada dentro da dimensão geopolítica de utilização e preservação dos recursos naturais do planeta. Dada a possibilidade de a crise se consolidar em nível global, a água deixará de ser tratada como bem comum para se tornar um bem econômico.

Nesse caso a água passa, portanto, a adquirir um valor econômico em função de sua contribuição para grande número de atividades produtivas e industriais. A Amazônia assume assim uma posição internacional de forte conteúdo geopolítico. Barros explica que:

por apresentar um território muito amplo e uma disponibilidade hídrica superior à de muitos países, a Bacia Amazônica Brasileira se transforma num local estratégico de valor econômico e social, que perpassa pelo entendimento de que a referida bacia é primordial à sobrevivência da biodiversidade da Amazônia e, consequentemente, do mundo [...] alterou-se o significado da Amazônia, com uma valorização estratégica de dupla face: a da sobrevivência humana e a do capital natural, sobretudo as florestas, a megadiversidade e a água. (2006: 110)

Um dos aspectos mais importantes das relações internacionais do momento compreende a crise da água e as repercussões geopolíticas sobre a Amazônia. Ribeiro enfatiza que: "as previsões sobre a evolução da crise mundial da água têm uma repercussão sobre a Amazônia geopoliticamente preocupante [...] pode-se concluir que, diante da fragilidade geopolítica da Amazônia, esse aspecto não deixará de estar na agenda das discussões para a solução da crise mundial da água" (2006: 385).

Comentando sobre uma ética para a água, dentro do novo panorama internacional, Tundisi indica que: 
quando a água é abundante e o volume per capita é muito alto, como nas regiões da bacia Amazônica ou em alguns lagos africanos, os vários aspectos dos usos múltiplos podem coexistir sem graves problemas. Entretanto, é na escassez que os conflitos sobre a água emergem e a competição se acirra [...] Um dos grandes desafios do século XXI deverá ser a resolução e o acompanhamento de conflitos internacionais resultantes da disputa da disponibilidade de água. (2003: 193)

Diante dos possíveis conflitos internacionais por causa da escassez de água em determinadas regiões do mundo, a Bacia Hidrográfica Amazônica, que apresenta elevado potencial hídrico de valor estratégico, econômico e social exige, por parte do Governo brasileiro, formulação de políticas públicas dirigidas a fortalecer a integração regional da Amazônia como forma de confrontar os constantes discursos internacionais dirigidos a definir uma dinâmica geopolítica sobre a maior fronteira de capital natural do planeta.

\section{A Amazônia diante do novo contexto global}

A globalização das atividades financeiras, econômicas e sociais é uma realidade que não pode ser ignorada. Esse processo tem gerado tanto oportunidades como preocupações, com a crescente desigualdade das forças do mercado atuando nos diferentes setores da economia internacional. Estimulada a globalização, a partir de 1980, pelas inovações tecnológicas nos setores de comunicação e biotecnologia, a nova ordem internacional imposta à maioria dos países em desenvolvimento tem sido bastante assimétrica.

Aquelas economias que conseguiram aproveitar esse potencial de crescimento econômico e integração regional elevaram, significativamente, seus indicadores econômicos e sociais. Os países, por outro lado, que se limitaram a "presenciar" o processo globalizante das economias internacionais, enfraqueceram suas posições de participação no comércio internacional e reduziram suas taxas de fluxos de capital.

Sobre esse aspecto, Ribeiro é bem explícito ao argumentar sobre o facto de que "uma estratégia fundamental que o Governo brasileiro deve adotar para evidenciar objetivamente a soberania do Brasil sobre a Amazônia é a adoção de medidas relativas à implantação de infraestruturas que tornem mais efetiva a integração da Amazônia ao restante do país" (2006: 397). As alterações decorrentes do processo de globalização nos serviços de produção, industrialização e comercialização trouxeram novas responsabilidades para os diferentes setores do Governo brasileiro, responsáveis pela implementação das políticas públicas nacionais dirigidas a incentivar a 
preservação ambiental, garantir a administração dos recursos naturais estratégicos - águas, biodiversidade, minerais - e promover políticas regionais visando a fortalecer as políticas públicas de desenvolvimento sustentável da Amazônia.

A globalização trouxe para a Amazônia, por um lado, a possibilidade de participar na transformação do contexto do comércio internacional; por outro lado, trouxe também a exigência de preservar, nesse novo cenário de processos tecno-industriais intensivos em recursos naturais, sua soberania territorial. Nesse contexto, a Amazônia, diante da forte pressão global pela disponibilidade de recursos naturais estratégicos para a manutenção do padrão de desenvolvimento e crescimento econômico atual, assume, como espaço vital do século XXI, importância geopolítica mundial.

\section{Considerações finais}

As modificações nos padrões produtivos internacionais decorrentes do processo de globalização, instalado a partir de 1980, têm influenciado significativamente as políticas econômicas, sociais e ambientais na maior parte dos espaços geográficos do planeta. A globalização ofereceu, sem dúvida, ótimas oportunidades para o desenvolvimento econômico daqueles países que, ao ampliar seus investimentos, incorporaram importantes transformações nos setores de forte inovação tecnológica.

A internacionalização da economia mundial criou novas dimensões econômicas e geopolíticas, caracterizando um ordenamento global no qual a incorporação de recursos estratégicos se tornou a regra do mercado. A Amazônia, por ser uma região de dimensões continentais e detentora de grandes estoques de recursos estratégicos, passou a ser parte dessa maior interdependência dos mercados. Na nova dinâmica internacional pela busca e apropriação de recursos estratégicos necessários para o crescimento da economia global e preservação das posições hegemônicas das grandes potências, a segurança e a soberania da Amazônia exigem crescente envolvimento do Governo brasileiro para definir projetos regionais que determinem e reorientem as políticas públicas.

As diferentes regiões que detêm grande parte dos recursos naturais estratégicos, para as atividades econômicas e produtivas do século XXI, serão os centros determinantes da mobilização de alternativas políticas e estratégias internacionais dirigidas a assumir o controle das reservas de recursos estratégicos. A biodiversidade, os recursos minerais e as grandes reservas de água doce da Amazônia têm exercido, historicamente, enorme interesse de apropriação por parte de vários países e instituições internacionais. Caracterizados pelas forças do mercado internacional como importantes 
recursos para sobrevivência da humanidade, eles provocam as mais absurdas iniciativas de internacionalização da região Amazônica, desconsiderando completamente a noção da soberania brasileira.

\section{Referências bibliográficas}

Barlow, Maude; Clarke, Tony (2002), Blue Gold: The Fight to Stop the Corporate Theft of the World's Water. New York: The New Press.

Barros, F. G. N. (2006), "A Bacia Amazônica Brasileira no contexto geopolítico da escassez mundial de água”. Dissertação de Mestrado em Economia apresentada à Universidade da Amazônia, Belém, Brasil.

Becker, Bertha K. (2004), Amazônia: geopolítica na virada do III milênio. Rio de Janeiro: Garamond.

Becker, Bertha K. (2005), "Geopolítica da Amazônia”, Estudos Avançados, 19(53), 71-86.

Camdessus, Michel; Badré, Bertrand; Chéret, Ivan; Ténière-Buchot, Pierre-Frédéric (2005), Água: oito milhóes de mortos por ano, um escândalo mundial. Rio de Janeiro: Bertrand Brasil.

CETEM - Centro de Tecnologia Mineral (1991), Recursos minerais da Amazônia: alguns dados sobre situação e perspectivas. Rio de Janeiro. Consultado a 17.02.2012, em http:// www.ambientebrasil.com.br.

Cohen, Bernard Saul (2003), Geopolitics of the World System. New York: Rowman \& Littlefield Publishers.

Clarke, Robin; King, Jannet (2005), O atlas da água. São Paulo: Publifolha.

Da Silva, G. G. (1996), "Recursos minerais da Amazônia: usos, desusos e abusos", in Crodowaldo Pavan (org.), Uma estratégia latino-americana para a Amazônia, vol. 2. São Paulo: UNESP, 205-208.

De Villiers, Marq (2002), Água. Rio de Janeiro: Ediouro.

Dos Santos, Breno Augusto (1980), Amazônia: potencial mineral eperspectivas de desenvolvimento. São Paulo: Editora T. A. Queiroz.

Dos Santos, Breno Augusto (1996), "Potencial mineral da Amazônia para o século XXI e os problemas ambientais relacionados", in Crodowaldo Pavan (org.), Uma estratégia latino-americana para a Amazônia, vol. 2. São Paulo: UNESP, 175-204.

Gama, G. N. W. (1997), "O Projeto Dinâmica Biológica de Fragmentos Florestais - PDBFF (INPA/SMITHSONIAN): Uma base científica Norte-Americana na Amazônia Brasileira”. Dissertação de Mestrado Internacional em Planejamento do Desenvolvimento apresentada ao Núcleo de Altos Estudos Amazônicos da Universidade Federal do Pará, Belém, Brasil.

Gleick, Peter H. (1993), Water in Crisis: A Guide to the World's Fresh Water Resources. New York: Oxford University Press. 
ICA - Intelligence Community Assessment (2012), "Global Water Security”. Consultado a 15.03.2014, em www.dni.gov/files/documents/Special\%20ReportICA\%20 Global\%20Water\%20Security.pdf.

Inovação Tecnológica (2008), "Besouro brasileiro tem a chave para computadores ópticos do futuro”. Consultado a 17.12.2013, em http://www.inovacaotecnologica.com. $\mathrm{br} /$ noticias/noticia.php? artigo= besouro-brasileiro-tem-a-chave-para-computadoresopticos-do-futuro.

Lavilla, E. O. (1996), "Reflexiones sobre la protección de la biodiversidad Amazónica”, in Crodowaldo Pavan (org.), Uma estratégia latino-americana para a Amazônia, vol. 1. São Paulo: UNESP.

Klare, Michael (2002), Resource Wars: The New Landscape of Global Conflict. New York: Henry Holt and Company.

Klare, Michael (2008), "A nova geopolítica da energia”. Consultado a 20.01.2014, em http://www.ecodebate.com.br/2008/05/26/a-nova-geopolitica-da-energia-artigo-demichael-t-klare/.

Lechner, Frank J. (2009), Globalization: The Making of World Society. New Jersey: Wiley-Blackwell.

MME - DNPM - Ministério de Minas e Energia, Departamento Nacional de Produção Mineral (2006), "Informe Mineral Regional - Amazônia 2006”.

Ministério do Meio Ambiente (2001), Avaliação e identificação de ações prioritárias para a conservação, utilização sustentável e repartição dos benefícios da biodiversidade na Amazônia brasileira. Brasília.

ONU (2012), World Water Development Report 4. Paris.

Revilla, Juan (2000), Plantas da Amazônia: oportunidades econômicas e sustentáveis. Manaus: SEBRAE/AM.

Ribeiro, Nelson de Figueiredo (2006), A questão geopolítica da Amazônia: da soberania difusa à soberania restrita. Belém: EDUFPA.

Schmidt, Paulo; Santos, José Luiz dos (2002), Avaliação de ativos intangiveis. São Paulo: Atlas.

Shiva, Vandana (2001), Biopirataria: a pilhagem da natureza e do conbecimento. Petrópolis: Vozes.

Shiva, Vandana (2002), Water Wars: Privatization, Pollution, and Profit. Toronto: Between the Lines Press.

Stiglitz, Joseph Eugene (2003), Globalization and its Discontents. New York: W. W. Norton \& Company.

Tosta, Octávio (1984), Teorias geopolíticas. Rio de Janeiro: Biblioteca do Exército Editora.

Tundisi, José Galizia (2003), Água no século XXI: enfrentando a escassez. São Carlos: Rima.

UNESCO (2003), Agua para todos, agua para la vida. Paris. 
Villas, Raimundo Netuno (2008), "Megapotencialidades minerais. Amazônia: a floresta e o futuro", Scientific American Brasil - Amazônia, 2, 76-83.

Artigo recebido a 18.09.2014

Aprovado para publicação a 20.04.2015

\section{Mario Miguel Amin}

Núcleo de Altos Estudos Amazônicos, Universidade Federal do Pará

Av. Perimetral, Número 1 - Guamá,

66075-750 Belém, Pará, Brasil

Contacto: marioamin@gmail.com

\section{The Amazon in World Geopolitics of the Strategic Resources of the Twenty-first Century}

The purpose of this article is to discuss the geopolitically strategic position of the Amazon region in the context of the scarcity of the strategic natural resources needed for the growth of the world economy in the twenty-first century. Since the 1980s, the globalization paradigm has defined a new geopolitical configuration determined by the growing international demand for strategic natural resources. In this new global environment, the search for "vital areas" has become a critical factor for those hegemonic economies which have, for centuries, decreed the course of international trade. In this process, those regions rich in strategic resources have thus been the centre of international attention. The Amazon region, which holds the largest stock of strategic resources - water, minerals, biodiversity - on the planet, is set to be the vital area of the twenty-first century. A new geopolitical reality is being established for the Amazon region, demanding a greater state presence not

\section{L'Amazonie dans la géopolitique mon- diale des ressources stratégiques $d u$ xxıème siècle}

Le but du présent article est de se pencher sur la position géopolitiquement stratégique de la région amazonienne face aux perspectives mondiales de raréfaction de ressources naturelles stratégiques nécessaires à la croissance de l'économie mondiale au xxıème siècle. Le paradigme de la mondialisation a défini, à partir des années 1980, une nouvelle configuration géopolitique déterminée par l'incessante demande internationale de ressources naturelles stratégiques. Dans cette nouvelle conjoncture globale, la recherche de "territoires vitaux" est devenue un facteur critique pour ces économies hégémoniques qui, pendant des siècles, ont tracé la voie du commerce international. Au cours de ce processus, les régions riches en ressources stratégiques sont ainsi devenues le centre des attentions internationales. La région amazonienne, détentrice de la plus importante réserve de ressources stratégiques - eau, minéraux, biodiversité - de la planète, constitue dès lors l'espace vital du 
only to achieve its economic growth and sustainable development but to reaffirm the sovereignty of the region, too.

Keywords: Amazon; geopolitics; globalization; natural resources; regional sovereignty. xxième siècle. C'est ainsi qu'une nouvelle réalité géopolitique pour la région amazonienne se fait jour, exigeant une présence de l'État plus importante, ayant pour but non seulement sa croissance économique et son développement durable, mais aussi la réaffirmation de sa souveraineté dans la région.

Mots-clés: Amazonie; géopolitique; mondialisation; ressources naturelles; souveraineté régionale. 
